\title{
Top Secrets to Growing University Research in Uncertain Times
}

\author{
Prem Paul, Vice Chancellor for Research and Economic Development, \\ University of Nebraska \\ Monica Norby, Assistant Vice Chancellor for Research, \\ University of Nebraska \\ Nathan Meier, Director of Research Strategy, University of Nebraska
}

I

$t$ is no secret that the budgetary environment for academic research funding has been more challenging than ever during the last six years. Flat federal funding for academic science and engineering research, increased competition and lower success rates for grants, heightened rivalry for top faculty talent and a larger burden of costs for research compliance make these uncertain times for university research. Despite these challenges, it is more important than ever that universities continue to grow their research enterprise.

Universities perform much of the basic research essential to the nation's long-term competitiveness, contributing to technology development and stimulating economic growth at the local, state and national levels. Unfortunately, recovery from the recession of 2008 has been slow, debt levels are high and the national budget deficit is huge, leading to an increased focus on cutting federal discretionary spending - the source of more than half of academic research funding.

Funding for Academic Research

The federal government has been the primary source of funding for academic research and development for more than 50 years $^{1}$. In FY2008, the federal government provided approximately 60 percent of an estimated $\$ 51.9$ billion of research and development funds expended by academic institutions ${ }^{2}$. While there have been increases in funding, and the numbers can be sliced and diced different ways, the main story is that federal obligations for science and engineering to universities and colleges have essentially been flat, even prior to the 2008 recession. Since the recession, sequestration has hit funding hard at some key funding agencies, especially the National Institutes of Health, where sequestration in FY2013 lowered appropriations by more than 5 percent or $\$ 1.55$ billion below the previous fiscal year ${ }^{3}$.

Federal expenditures for science and engineering academic R\&D increased 4.5 percent from 2009 to 2012 compared to 0.6 percent from 2005 to 2008. But the higher growth rates in the later years largely reflect American Recovery and Reinvestment Act of 2009 (ARRA) expenditures. The 11.0 percent decrease in 
current dollars from FY2010 federal obligations ( $\$ 35.3$ billion to 1,219 academic institutions) reflects the absence of ARRA stimulus funds in FY2011. The last ARRA funds were obligated in FY2010 and accounted for 14.5 percent of FY 2010 S\&E obligations to academic institutions. Universities reported $\$ 4.2$ billion in expenditures funded by ARRA in FY 2011 and an additional $\$ 2.4$ billion in ARRA expenditures in FY2012. The loss of ARRA funds has created a negative "cliff effect," with most academic institutions seeing their federal funding decrease during the last two years.

The NIH is by far the largest funder of academic research, providing about 56 percent of total federal academic S\&E R\&D expenditures in FY 2012. The National Science Foundation and Department of Defense are the next largest, each providing between 12 and 13 percent of the total funding. The Department of Energy, National Aeronautics and Space Administration and U.S. Department of Agriculture provided smaller shares of between 3 and 5 percent of the total in FY $2012^{4}$.

Institutional and State Funds. Other sources of research funding also have been flat or faced reductions. In FY2012, institutional funds - self-funding - from universities and colleges comprised the second-largest source of funding for academic S\&E R\&D, more than 19 percent of the total, a number that has been fairly steady since 1990. This institutionally financed R\&D also includes unrecovered indirect costs and committed cost sharing ${ }^{4}$.

Public universities, which rely on state funding, have seen this source reduced as state economies struggle and non-discretionary budget spending grows. From 1992 to 2010, state appropriations as a percentage of public research universities' total revenue fell by 15 percentage points, from 38 percent in 1992 to 23 percent in 2010. At the same time, student enrollment from 2002 to 2010 increased 13 percent, and state spending per student failed to keep up. The result: state funding per enrolled student dropped 20 percent during this time and hit a 25-year low in $2011^{6}$.

Together, these numbers add up to uncertain times for academic research funding that have wide-ranging effects on our institutions' research faculty and the nation's research enterprise.

Greater Competition for Fewer Dollars. Research is a growing part of the

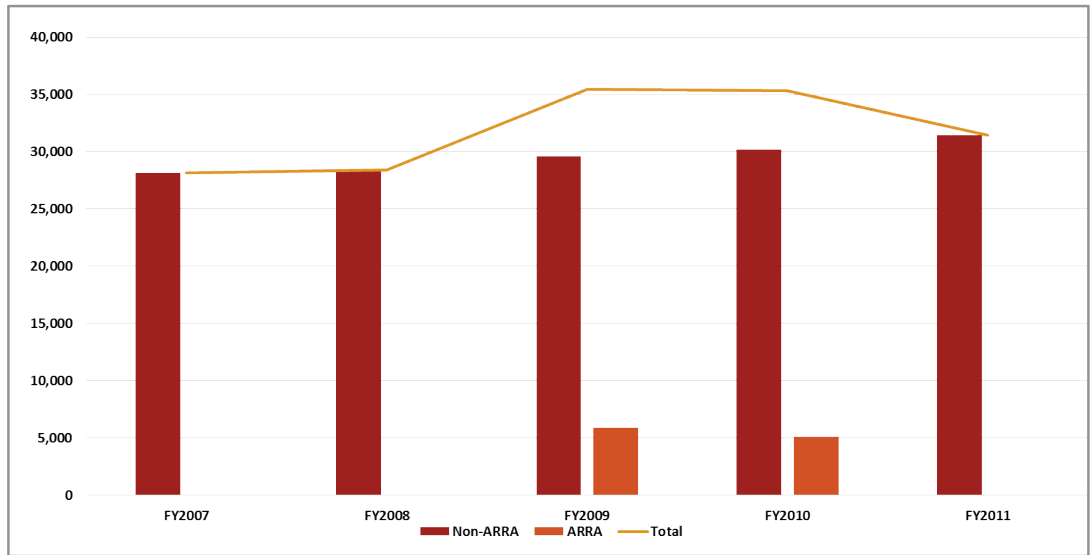

Federal Academic S\&E Obligations 2007-2011.

Source: NSF Statistics, NSF 14-309, "Federal Science and Engineering Obligations to Universities and Colleges Drop by 11 percent in FY2011," Michael Yamaner. Total Federal obligations for S\&E US-wide in FY2011 was $\$ 128$ billion. 
mission of universities, including those who may not have emphasized it in the past. Strong research programs are key to a university's reputation and attract talented faculty, students and donors. As universities push faculty to grow their research programs, more and more researchers are applying for the flat, or sometimes reduced, pool of funds. Competition for research funds has never been more intense, and funding rates are dropping.

The success rate for NIH R01 grants, award total has been reduced - as has been the level of faculty summer salary covered by NSF awards.

The average number of months of salary support for individual Principal Investigators continued its 10-year decline and is now just over 0.8 months, down from 1.5 months in 2004. Additionally, during the last two years, the number of requests for proposals has declined, and some of the NSF programs have reduced the number of submissions from twice to once annually.

the bread and butter of biomedical research, has dropped from 32 percent in 2001 to 17 percent in 2013 - an historic low. Nearly all $\mathrm{NIH}$ funding metrics, from the number of new awards, average size of awards and total amount of funding for research grants, declined in 2013 due to the 5 percent decline in appropriations due to sequestration ${ }^{3}$.

At NSF, the success rate for competitively reviewed proposals in 2013 was 22 percent, the lowest rate since 2001. The funding rate varies by NSF Directorate, from a low of 18 percent in Education and $\mathrm{Hu}-$ man Resources to a high of 26 percent in Geosciences $^{6}$. The average

\section{NSF Proposal Success Rates}

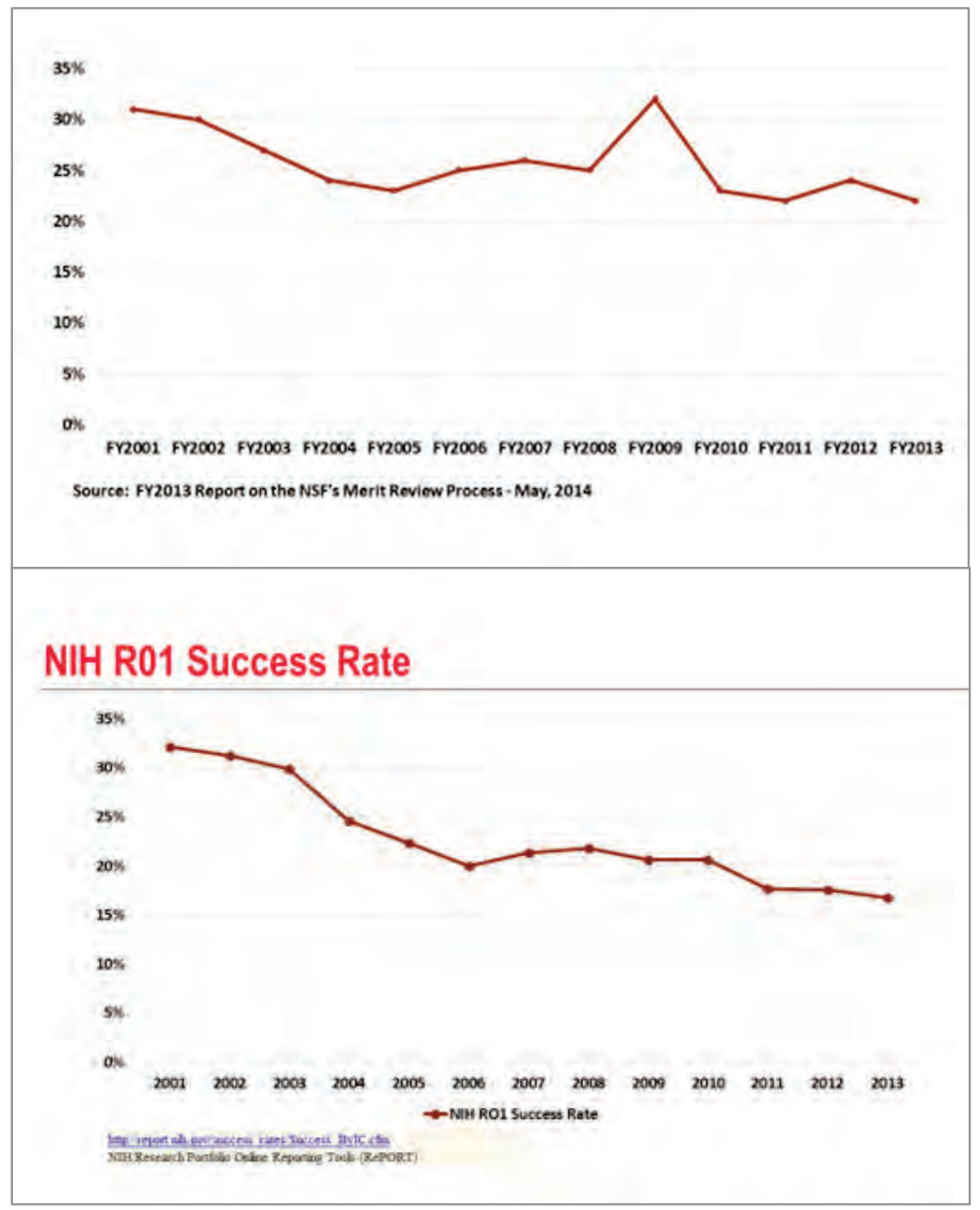


These trends can have profound effects on a researcher's career. A scientist may not receive her first NIH R01 grant until age 40 or older, following several submissions and rejections. Researchers spend more and more time developing and submitting grants, with less chance of success. Thus, the demand for faculty who are well-funded or have shown the potential to bring in funding is increasingly intense.

Greater Competition for Talent. The quality of any research program depends on its faculty talent, and the competition for both talented faculty and students is intense. Institutions understand the value of proven, talented faculty who are visionary and have track records of establishing competitive, externally-funded research programs. These faculty can instantly enhance the research competitiveness and stature of an institution and can also provide leadership in successfully competing for large grants. There also is increased demand for entrepreneurial faculty who can translate research into technologies and solutions through partnership with clinicians, industry and start-up companies.

Recruitment and retention of faculty has become a top priority at most institutions, and this is driving increases in salaries and especially in start-up packages. Recruits are demanding larger packages as they recognize the competition among recruiting institutions and their own power to negotiate. In the life sciences, physical sciences and engineering, startup packages can total more than $\$ 1$ million for faculty in high-demand areas. This trend is not sustainable.

\section{Successful Approaches for Build-} ing University Research

We have had good success in growing our research enterprise at the University of Nebraska-Lincoln during the last decade. In a recent 10-year span, UNL ranked seventh among all major U.S. research universities in the percentage growth in total NSF R\&D federal research expenditures. We have used multiple approaches to achieve this growth, aiming for quick success in key areas and building for the longer term in other areas. Investments have to be made in many areas, ranging from faculty talent and centers of excellence, to infrastructure and partnership building. Data is invaluable in this kind of strategy, and one of our first investments was the development of NUgrant, an in-house research administration system used to manage all aspects of research activity.

What the UNL data tell us. At UNL, a small number of faculty earn the vast majority of the institution's research funding. During the last four years, 5 percent of faculty brought in more than 50 percent of UNL's federal research funding. Twenty-five percent of faculty brought in 90 percent of the funding.

The majority of our funding come in larger grants: 16 percent of research grants are for more than $\$ 1$ million, but they account for more than 50 percent of our research funding. A majority of our top-funded faculty are affiliated with centers or major initiatives, but the largest percentage of our faculty have single grants rather than multiple or collaborative projects. 
Single investigator-initiated grants vs interdisciplinary centers or program projects. The relative merits of funding agency support for individual investigator-initiated grants versus larger team science grants has been the subject of extensive discussion in the scientific community. The argument for investigatorinitiated grants such as the NIH R01 is that these make up the strong investigator-inspired, fundamental research base that produces innovative ideas and major discoveries. Larger, team-science based approaches, it is argued, are required to address major societal challenges and are best supported through center and program project funding mechanisms.

Both approaches are needed, and the federal agencies maintain a balance. In 2013, NIH invested $\$ 2.799$ billion in 769 research center grants and $\$ 14.9$ billion on 49,581 research project grants (R01, R15, R21). NSF invested $\$ 1.2$ billion in single PI grants and $\$ 2.1$ billion on multiple investigator grants.

At UNL, our data show that half of our federal funding comes in grants of $\$ 1$ million and larger, and a significant amount comes through grants to interdisciplinary teams and center grants. Our current large multi-disciplinary grants and centers include NIH Centers of Biomedical Research Excellence in virology, redox biology and obesity research; an NSF-funded Materials Research Science \& Engineering Center in quantum and spin phenomena in nanomagnetic structures, a large NSF-funded project on the Large Hadron Collider and a USDA Coordinated Agricultural Project aimed at detecting and preventing E. coli infection throughout the beef production pipeline.
All of these, and many of our other large projects, include partners from other institutions. These multi-institutional collaborations are critical to our ability to win large awards.

Like the federal agencies, we have to balance our investments in single investigator and inter-disciplinary centers and large teams. We have to invest in the future by hiring top junior faculty, nurturing their careers and building their leadership skills. At the same time, we are investing in centers of excellence through targeted hires, fostering collaborations with other institutions and the private sector, and building infrastructure to support research.

Faculty hires in Programs of Excellence. A decade ago, we decided that the best way to grow our research enterprise was to invest in a small number of areas where we were already strong or where we needed to be stronger to address research challenges important to Nebraska and the nation. Our Programs of Excellence funding and other funds enabled us to hire new faculty, both senior and junior, in these targeted areas. Multi-disciplinary cluster hires enabled us to build strong teams in a short time. Areas in which we have invested central resources include materials and nanoscience, atomic and molecular physics, virology, early childhood education, water and food security, computational sciences and digital humanities.

Developing faculty leadership. Key to building successful research programs are visionary faculty who are also willing to lead faculty teams and pursue collaborative research. We support junior faculty 
leadership development through our Research Development Fellows Program, a focused year-long experience of formal and informal learning sessions designed to help early stage investigators conceptualize project plans, interact effectively with program officers, identify funding opportunities, plan and draft effective grant proposals and develop an understanding of the proposal review process. We also provide a variety of targeted workshops for faculty, including those on successful proposal writing, faculty career development award programs, interacting with specific agencies like the Department of Defense and strategies for integrating research and education to achieve broader societal impact.

Research Competitiveness Support. In today's tough budget environment, proposals have to be top quality with innovative ideas that are well presented. We created an office that provides support to faculty from idea generation to facilitating team building and external review of proposals prior to submission to funding agencies. This mechanism is very much utilized and appreciated by faculty, especially for large multi-investigator grants. Our faculty have benefited from these services, which have increased their funding success. This focus on enhanced grantsmanship also includes developmental assistance with graphics and generation of grant proposal budgets.

Shared Facilities. The traditional model for faculty hires provides start-up packages to purchase equipment to be located in the faculty member's laboratory. Often this equipment is not accessible to other faculty. Our approach is to require that multi-user equipment be placed in department-wide or university-wide shared instrumentation facilities. During the last three years, we have built four such shared instrumentation facilities. A few examples:

- The Volte-Keegan Nanoscience Research Center, which houses a shared instrumentation core facility to support our faculty research in nanoscience and materials science. The building was partially funded through a competitive ARRA grant

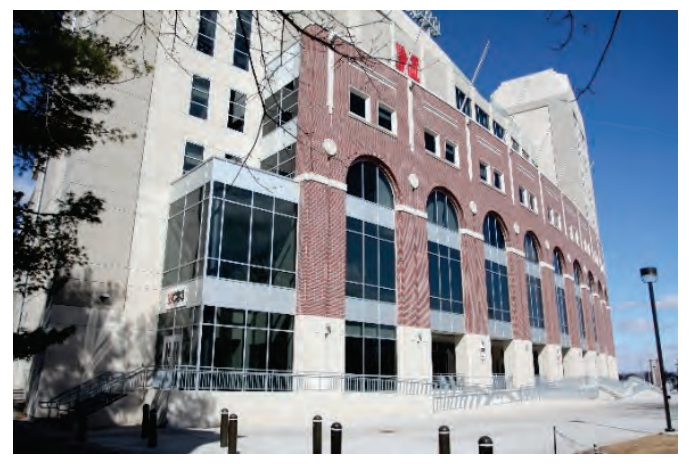

from the National Institutes of Standards and Technology. The 32,000-square-foot facility is equipped with clean room space and equipment for making and characterizing nanomaterials provides centralized research facilities for more than 80 physics, chemistry, engineering and other faculty members.

- The Extreme Light Laboratory is home to one of the nation's leading programs in laser research and has created an extensive infrastructure, including the Diocles laser, one of the world's most powerful compact lasers, delivering up to 1 petawatt of power. In 2014 a new specialized laser Archimedes, housed in a facility designed for multiple research 
teams added to our capabilities. The multi-user facility was funded by ARRA funds from NSF and the laser was funded through an Air Force Research Laboratory grant. The Extreme Light Laboratory is a truly collaborative effort, created through investments from UNL, the state of Nebraska, DoD and NSF.

- The Center for Brain, Biology and Behavior features shared research areas that encourage faculty collaboration, state-of-the-art equipment and a unique partnership between UNL research and athletics that deepens the university's growing expertise in concussion research. Other Center research ranges from uncovering the biological underpinnings of political leanings and the nature addiction to exploring the heritability of social attitudes and language development. It is one of the only labs in the world to simultaneously capture functional magnetic resonance imaging (fMRI), record brain electrical activity and track eye movement. The Center, which occupies half of a more than 50,000-square-foot addition to UNL's Memorial Stadium, is adjacent to the Nebraska Athletics Performance Lab, a collaborator on joint health and performance initiatives. NAPL provides shared facilities for investigating the impact of training interventions and nutrition on performance and recovery, assessing the biomechanical impact of performance on the athlete's body, harnessing biomarkers in saliva and blood to guide training, and developing technologies to reduce injury and improve performance.

Faculty engagement. Communication and engagement with faculty is absolutely critical to research success at UNL. The UNL Research Advisory Board, made up of top researchers from disciplines throughout the university was established in 2001. The RAB has provided crucial advice on the research agenda and in defining what is most important to faculty success. An early suggestion that has paid big dividends was to build connections among faculty through interdisciplinary faculty retreats in targeted thematic areas. The most recent retreat, held in May, 2014, involved more than 275 faculty from across campus, featured nationally recognized speakers and talks and "quick pitches" by UNL faculty, panel discussions, networking activities and breakout sessions focused on thematic areas developed in conjunction with the RAB members ${ }^{7}$. At the conclusion of the retreat, a new seed grant program designed to facilitate competitiveness for external funding was announced. These retreats have proven essential to build faculty connections and stimulate the level of cross-disciplinary collaboration and innovative thinking needed for long-term funding success.

\section{Conclusion}

In the current budgetary environment, research universities face a number of significant challenges related to the pursuit and capture of external funding, including the recruitment and retention of top faculty talent. This concept paper highlights some of the strategies that 
have enabled UNL to mitigate these challenges and maintain its research growth and progress. Data-driven decision making, emphasis on individual investigator and team-based projects (including multi-institutional and interdisciplinary efforts), targeted hiring and infrastructure investments, and focused research and faculty development resources represent some of the strategies necessary to maintain market share and facilitate academic R\&D in the face of stagnant or diminishing extramural funding. Strategies such as these represent but a few of the secrets to success that may be adopted in whole or in part - by other institutions seeking to enhance their research profiles in these uncertain times.

\section{References}

National Science Board. 2012. Science and Engineering Indicators (p. 5-7). Arlington, VA: National Science Foundation)
National Science Foundation, "Universities Report \$55 Billion in Science and Engineering R\&D Spending for FY2009: Redesigned Survey to Launch in 2010," InfoBrief, NSF10-329, September 2010, p.1 http://nexus.od.nih.gov/all/2014/01/10/fy2013 -by-the-numbers/

National Science Board. 2014. Science and Engineering Indicators 2014. Arlington VA: National Science Foundation (NSB 14-01).

National Science Board. 2012. Diminishing Funding and Rising Expectations: Trends and Challenges for Public Research Universities, A Companion to Science and Engineering Indicators 2012, Arlington, VA: National Science Foundation (NSB12-45).

Report to the National Science Board on NSF'S Merit Review Process, 2013. Arlington, VA: National Science Foundation (NSB-14-32).

Office of Research and Economic Development, University of Nebraska-Lincoln. 2014. 2014 Interdisciplinary Faculty Retreat. Retrieved from http://research.unl.edu/facultyretreat14/. 